\title{
Phytochemical analysis of Viburnum davidii Franch. and cholinesterase inhibitory activity of its dihydrochalcones
}

\section{Lamberto Tomassini, Antonio Ventrone, Claudio Frezza, Anna Maria Fabbri, Stefano Fortuna, Maria Teresa Volpe \& Maria Francesca Cometa}

To cite this article: Lamberto Tomassini, Antonio Ventrone, Claudio Frezza, Anna Maria Fabbri, Stefano Fortuna, Maria Teresa Volpe \& Maria Francesca Cometa (2021) Phytochemical analysis of Viburnum davidii Franch. and cholinesterase inhibitory activity of its dihydrochalcones, Natural Product Research, 35:24, 5794-5800, DOI: 10.1080/14786419.2020.1837814

To link to this article: https://doi.org/10.1080/14786419.2020.1837814

View supplementary material $₫$

Published online: 23 Oct 2020.

Submit your article to this journal «

凹 Article views: 93

View related articles

View Crossmark data $\nearrow$

Citing articles: 2 View citing articles $匚$ 


\title{
Phytochemical analysis of Viburnum davidii Franch. and cholinesterase inhibitory activity of its dihydrochalcones
}

\author{
Lamberto Tomassini ${ }^{\mathrm{a}}$, Antonio Ventrone ${ }^{\mathrm{a}}$, Claudio Frezza ${ }^{\mathrm{a}}$ (D), Anna Maria \\ Fabbri $^{a}$, Stefano Fortuna ${ }^{b}$, Maria Teresa Volpe ${ }^{b}$ and Maria Francesca Cometa ${ }^{b}$ \\ aDepartment of Environmental Biology, "La Sapienza" University, Rome, Italy; ${ }^{\text {b}}$ National Center for \\ Drug Research and Evaluation, Istituto Superiore di Sanità, Rome, Italy
}

\section{ABSTRACT}

One flavonoid (quercetin, 1) and three dihydrochalcones $\left(6^{\prime \prime}-O-p\right.$ hydroxybenzoyl-davidioside, 2, 4'-O-methyl-davidioside, 3, and davidioside, 4) were isolated from the leaves and young branches of Viburnum davidii Franch. All the structures were identified by comparison of their spectroscopic data (NMR and MS) with those present in literature. In addition, compounds 2-4 were evaluated for their cholinesterase inhibitory (ChEl) activity, for the first time. Accordingly, compounds $\mathbf{2}$ and $\mathbf{4}$ showed significant inhibition of both acetylcholinesterase (AChE) and butyrylcholinesterase (BChE) with $I_{50}$ values equal to 36.883 and $39.274 \mu \mathrm{M}$, respectively for the former and 39.504 and $43.101 \mu \mathrm{M}$, respectively for the latter.
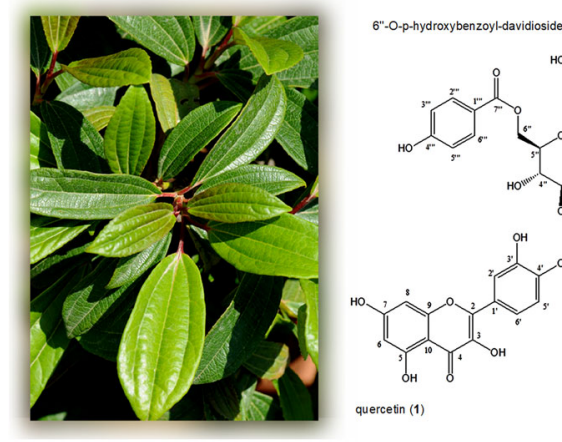

quercetin (1)

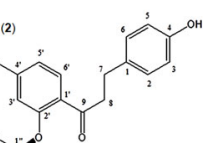

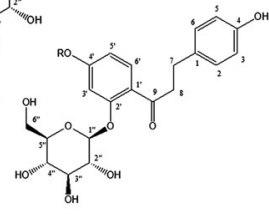

$R=M e: \quad 4^{\prime}-O-m e t h y l d a d i s s i d e(3)$

$R=H: \quad$ davidioside (4)

\section{ARTICLE HISTORY}

Received 14 July 2020

Accepted 29 September 2020

\section{KEYWORDS}

Viburnum davidii Franch; adoxaceae; phytochemical analysis; dihydrochalcones; acetylcholinesterase inhibitory activity; butyrylcholinesterase inhibitory activity

\section{Introduction}

Viburnum L. is a genus of flowering shrubs or small trees belonging to the family Adoxaceae (Winkworth and Donoghue 2005). This genus includes more than 200 species native to the temperate regions of the Northern Hemisphere, especially Central and Eastern Asia (Melchior 1964), where they are widely recommended as ornamental

CONTACT Lamberto Tomassini lamberto.tomassini@uniroma1.it

$(+)$ Supplemental data for this article can be accessed at https://doi.org/10.1080/14786419.2020.1837814.

(C) 2020 Informa UK Limited, trading as Taylor \& Francis Group 
plants (Kenyon 2001). Nevertheless, the main importance of the genus is related to the pharmacologic activities of some species that are still used in phytotherapy. The most important is Viburnum prunifolium L., a North American shrub, whose root and stem barks are well-known for their spasmolytic, sedative, and anti-asthmatic properties (British Herbal Pharmacopoeia 1983; Upton 2000; Cometa et al. 2009). Yet, many other species, such as V. trilobum Marshall, V. cotinifolium D.Don, V. grandiflorum Wall. ex DC., V. opulus L., V. nervosum D.Don and V. lantana L., have been used in ethnomedicine for their high anti-inflammatory, antidiabetic, sedative, antispasmodic, antiasthmatic, antiarrhythmic, antitumor, antimicrobial and antinociceptive properties (Yılmaz et al. 2007; Van et al. 2009; Awan et al. 2013; Saltan et al. 2016).

Viburnum davidii Franch. is quite rare as spontaneous plant, growing only in the mountain regions of Sichuan in Western China, but, starting from the $20^{\text {th }}$ century, it has been greatly imported in Europe for ornamental purpose. From a morphological standpoint, $V$. davidii is characterized by a tall and branched stem that tends to expand horizontally. The leaves are large, glossy, oval, glabrous and shiny, with slightly dentate margin and three big longitudinal and parallel veins. The flowers are tiny and white and are produced in late spring, densely grouped in stiff cymes. The fruits are ovoid, bright blue, produced in late summer and eaten especially by birds (Kenyon 2001).

In literature, only few works are present about this species mainly concerning phylogenetic, evolutionary and botanical aspects (Winkworth and Donoghue 2004; Jacobs et al. 2008; Chatelet et al. 2013), whilst only one work deals with its phytochemical constituents even if partially (Jensen et al. 1977). The lack of phytochemical information on V. davidii prompted us to start the current work, which, moreover, represents the continuation of a series of researches carried out in our laboratory on Viburnum genus (Tomassini et al. 2013). Other goals were to provide chemosystematic information on this species and to study the potential pharmacological properties of its main components, since, as it is known, plants with medicinal properties are of vital importance for human beings in the treatment of a wide array of diseases (Mohammadhosseini et al. 2019). In the second part of this work, having highlighted for the first time in V. davidii, the presence of flavonoids and dihydrocalcones, the pharmacological study was oriented to confirm the well-known anticholinesterase activity of these compounds, characterized by interesting potential application for the treatment of degenerative diseases such as Alzheimer's disease (AD). In this perspective, polyphenolic compounds with inhibitory power comparable to those of the currently prescribed AChE inhibitor drugs against $A D$ are still to be found, but they have the great advantages of being more tolerable and cheaper as they are commonly consumed in food.

\section{Results and discussion}

\subsection{Phytochemistry and chemotaxonomy}

The phytochemical analysis conducted on a cultivated exemplar of $V$. davidii led to the isolation and identification of four known compounds: quercetin (1), 6"-O-phydroxybenzoyl-davidioside (2), 4'-O-methyl-davidioside (3) and davidioside (4) (Figure 1). 


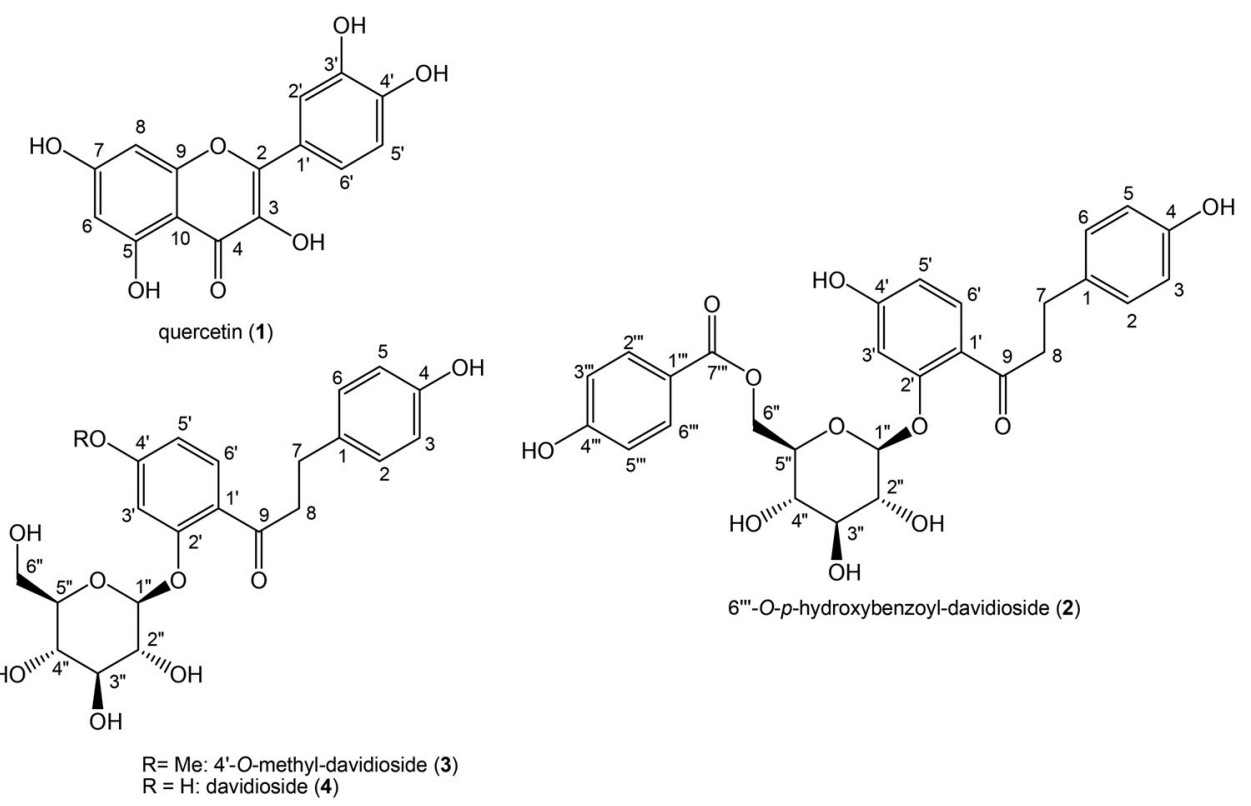

Figure 1. Structures of the identified compounds in $V$. davidii.

These compounds belong to two different classes of natural substances i.e., flavonoids (sub-class flavonols) for compound $\mathbf{1}$ and dihydrochalcones for compounds (2-4).

To the best of our knowledge, compounds $\mathbf{1}$ and $\mathbf{3}$ represent new phytochemicals for the species, whereas $\mathbf{2}$ is a newly reported compound for the family. In fact, quercetin (1) has been previously evidenced in several other Viburnum species such as $V$. dilatatum Thunb. (Kim et al. 2005), V. propinquum Hemsl.(Wang et al. 2009) and V. cylindricum Buch.-Ham. ex D. Don (Chen et al. 2008), whereas 4'-O-methyl-davidioside (3) has been previously evidenced only in V. lantanoides Michx. (Jensen et al. 1977). Within the family, the former compound seems to be quite frequent since it has been identified in several species (Backlund and Bittrich 2016), while compound 3 is less common and, in fact, its occurrence is limited to only one specific Viburnum species as previously described making a possible chemotaxonomic marker at the genus level.

$6^{\prime \prime}-0$-p-hydroxybenzoyl-davidioside (2), is the rarest of the isolated compounds, since it has been previously identified, together with (3), only in Anneslea fragrans var. lanceolata (Pentaphylacaceae) (Huang et al. 2012) consequently, it is an absolute novelty for the genus Viburnum, as well as for the Adoxaceae family. Lastly, davidioside (4) has been previously reported in V. davidii and in V. lantanoides (Jensen et al. 1977). Among the other entities of the family, the occurrence of this compound is also considered to be extremely rare, so that (4) could be considered as a potential chemosystematic marker of the species $V$. davidii.

\subsection{Cholinesterase inhibitory activity}

Dihydrochalcones are well-known to possess several interesting beneficial pharmacological properties, i.e., antioxidant, antiradical, antimicrobial, antifungal, insecticidal, 
Table 1. $I C_{50}$ values of the tested compounds for their $\mathrm{AChE}$ and $\mathrm{BChE}$ activities.

\begin{tabular}{|c|c|c|c|c|}
\hline \multirow{3}{*}{ Compounds } & \multicolumn{4}{|c|}{$\mathrm{IC}_{50}(\mu \mathrm{M}) \pm$ S.E.M. ${ }^{\mathrm{a}}$} \\
\hline & \multicolumn{2}{|c|}{ AChE } & \multicolumn{2}{|c|}{$\mathrm{BChE}$} \\
\hline & & $R^{2}$ & & $\mathrm{R}^{2}$ \\
\hline 2 & $36.883 \pm 3.021$ & 0.860 & $39.274 \pm 0.491$ & 0.987 \\
\hline 4 & $39.504 \pm 1.121$ & 0.973 & $43.101 \pm 0.512$ & 0.956 \\
\hline 3 & Not yielded & & Not yielded & \\
\hline BW284c51 & $0.021 \pm 0.008$ & 0.82 & & \\
\hline iso-oMPA & & & $1.88 \pm 0.12$ & 0.953 \\
\hline
\end{tabular}

${ }^{\mathrm{a} S t a n d a r d}$ error of the mean of five assays, each of them carried out in triplicate.

Except for 3 at concentrations of 1-100 $\mu \mathrm{M}, 2$ and 4 inhibit mouse brain total ChE activity and serum ChE activity in a concentration-dependent manner. The highly selective AChE inhibitor, BW284c51 $(0.001-1 \mu \mathrm{M})$ and the highly selective BChE inhibitor, iso-OMPA, $(0.001-10 \mu \mathrm{M})$ were used as positive controls. $\mathrm{IC}_{50}$ was obtained by extrapolation from linear regression line of the $\mathrm{ChE}$ activity as function of each dihydrochalcone and positive controls concentrations. The significance of differences between the means was determined by one-way analysis of variance (ANOVA) and posthoc analysis was performed using Student-Newman-Keul's method for multiple comparison of means. The value of $p \leq 0.01$ was taken as the cut-off value to consider a difference statistically significant.

antidiabetic, antileishmanial, antimalarial, anti-inflammatory, antispasmodic and neuroprotective (Rivière 2016). Some dihydrochalcones derivatives, as well as several polyphenols compounds, have also been extensively reported to inhibit both AChE and BChE activities (Mehta et al. 2012; Szwajgier 2014). Remarkably, quercetin is one of the strongest polyphenols in inhibiting AChE and BChE activities (Szwajgier 2014; Balkis et al.2015). It is well-known that the flavonoid structure is implicated in the interaction with ChE enzyme. Based on in vitro study of different flavonoids, also supported by molecular docking studies, it has been evidenced that quercetin and analogs, exhibited strong hydrogen bond interactions with the important amino acids of AChE (Khan et al. 2009). The key role of cholinergic deficit in AD has been well-known for many years, therefore the most promising therapeutic strategy for activating central cholinergic functions has been the use of AChE inhibitors. (Brunton et al. 2011). A few AChE inhibitors, viz. egtacrine, donepezil, galanthamine and rivastigmine, have obtained a market approval for patients with mild-to moderate AD. However, they have limited effectiveness and different tolerability profiles (Galisteo et al. 2000; Kaur and Zhang 2000; Lane et al. 2006). Different studies suggest that AChE and BChE may have roles also in modulating other targets that may affect rates of $A D$ progression. Interestingly, much experimental evidence has focused on the role of $B C h E$ in the development of the amyloid-rich neuritic plaques which are considered as the most relevant focus of current therapeutic research for AD (Lane et al. 2006). Therefore, the search for promising new $C h E$ inhibitors for $A D$ therapy becomes relevant in examining activity towards both $\mathrm{AChE}$ and $\mathrm{BChE}$. The recent interest in the prevention and management of $A D$ has focused on naturally occurring AChE inhibitors, particularly from plants.

Based on these considerations, the three dihydrochalcones here isolated (2-4) were tested for ChE inhibitory activities using respectively mouse brain and serum as the source of $\mathrm{AChE}$ and $\mathrm{BChE}$. The single compound potency of ChE inhibition was also calculated by comparing their inhibitory activities to those of the highly selective AChE (BW284c51) and BChE (iso-OMPA) inhibitors (Table 1).

At concentrations of $1-100 \mu \mathrm{M}$, compounds 2 and 4 inhibited the mouse brain total AChE activity and the serum BChE activity in a concentration-dependent manner up to an average of $85 \%$ inhibition of the enzymatic activity. For brain AChE inhibitory activity, 
compounds 2 and $\mathbf{4}$ showed a similar order of potency, having $\mathrm{IC}_{50}$ values equal to $36.883 \pm 3.02 \mu \mathrm{M}$ and $39.504 \pm 1.12 \mu \mathrm{M}$, respectively. In a similar manner, for the serum BChE inhibitory activity, compounds $\mathbf{2}$ and $\mathbf{4}$ showed a similar order of potency being their $I_{50}$ values equal to $39.274 \pm 0.49 \mu \mathrm{M}$ and $43.101 \pm 0.51 \mu \mathrm{M}$, respectively. Indeed, compound 3 showed a very limited AChE and BChE inhibitory activity and, in both cases, $I C_{50}$ values were not yielded. It is noteworthy that the inhibitory effect shown by compounds $\mathbf{2}$ and $\mathbf{4}$ towards the activity of both AChE and BChE, decreases dramatically with compound 3. The latter compound, although having a structure very similar to the other two, has a methoxy group in position $4^{\prime}$, instead of the free hydroxyl. This hypothesis proves to be consistent with previous evidence on the role of substituents of the $A$ ring of the flavonoid structure, where hydroxy groups at position 5, 6 and 7 play a major role in inhibiting AChE activity. Indeed, the loss of any of these A-ring hydroxyl groups greatly decreases inhibitory activity (Balkis et al. 2015).

\section{Experimental and spectroscopic data}

(See Supplementary Materials).

\section{Conclusions}

The phytochemical study on the leaves and young branches of $V$. davidii has led to the purification of four metabolites: the flavonol quercetin (1) and three dihydrochalcones, namely 6"'-O-p-hydroxybenzoyl-davidioside (2), 4'-O-methyl-davidioside (3) and davidioside (4). Except for (4), the identified compounds were isolated for the first time from $V$. davidii and, moreover, (2) is a newly reported compound for the family.

Compounds (2-4) were evaluated, for the first time, as possible AChE and BChE inhibitors and compounds $(\mathbf{2}, \mathbf{4})$ displayed inhibition activity. On the other hand, compound $\mathbf{3}$ proved to possess very low activity.

Due to the promising inhibitory activity on AChE and BChE of the compounds isolated from this species, also considering that quercetin is one of the flavonoids with the highest activity as ChE inhibitor, $V$. davidii could be of interest to be further investigated also in in vivo studies, in order to speculate on a clinically relevant therapeutic potential.

\section{Disclosure statement}

The authors declare no conflict of interest.

\section{ORCID}

Claudio Frezza (D) http://orcid.org/0000-0002-2968-5264

\section{References}

Awan Zl, Rehman H, Ahmed MN, Yasin KA, Minhas FA, Zubair M. 2013. Antibacterial screening of leaves of wild Viburnum nervosum and Viburnum foetens of Azad Kashmir. Int J Pharm Sci Invent. 2(6):22-26. 
Backlund A, Bittrich V. 2016. Adoxaceae. In: Kadereit JW, Bittrich V, editors. Flowering plants. Eudicots. The families and genera of vascular plants, vol. 14. Berlin (Germany): Springer.

Balkis A, Tran K, Lee YZ. Ng K. 2015. Screening flavonoids for inhibition of acetylcholinesterase identified baicalein as the most potent inhibitor. J Agric Sci. 7(9):26-35.

British Herbal Pharmacopoeia. 1983. Viburnum prunifolium. Bourneumouth (UK): British Herbal Medical Association, Scientific Committee; p. 234.

Brunton L, Chabner B, Knollman B. 2011. Goodman \& Gilman's the pharmacological basis of therapeutics. 12th ed. New York (USA): McGraw-Hill; p. 252-253.

Chatelet DS, Clement WL, Sack L, Donoghue MJ, Edwards EJ. 2013. The evolution of photosynthetic anatomy in Viburnum (Adoxaceae). Int J Plant Sci. 174(9):1277-1291.

Chen XZ, Wu HF, Li GY, Lu SM, Li BG, Fang DM, Zhang GL. 2008. Iridoids from Viburnum cylindricum. HCA. 91(6):1072-1076.

Cometa MF, Parisi L, Palmery M, Meneguz A, Tomassini L. 2009. In vitro relaxant and spasmolytic effects of constituents from Viburnum prunifolium and HPLC quantification of the bioactive isolated iridoids. J Ethnopharmacol. 123(2):201-207.

Galisteo M, Rissel M, Sergent O, Chevanne M, Cillard J, Guillouzo A, Lagadic-Gossmann D. 2000. Hepatotoxicity of tacrine: occurrence of membrane fluidity alterations without involvement of lipid peroxidation. J Pharmacol Exp Ther. 294(1):160-167.

Huang HY, Ko HH, Jin YJ, Yang SZ, Shih YA, Chen IS. 2012. Dihydrochalcone glucosides and antioxidant activity from the roots of Anneslea fragrans var. lanceolata. Phytochemistry. 78: $120-125$.

Jacobs B, Donoghue MJ, Bouman F, Huysmans S, Smets E. 2008. Evolution and phylogenetic importance of endocarp and seed characters in Viburnum (Adoxaceae). Int J Plant Sci. 169(3): 409-431.

Jensen SR, Nielsen BJ, Norn V. 1977. Dihydrochalcones from Viburnum davidii and V. lantanoides. Phytochemistry. 16(12):2036-2038.

Kaur J, Zhang M-Q. 2000. Molecular modelling and QSAR of reversible acetylcholines-terase inhibitors. Curr Med Chem. 7(3):273-294.

Kenyon L. 2001. Viburnum. Woking (UK): The National Council for the Conservation of Plants and Garden (NCCPG).

Khan MTH, Orhan I, Senol FS, Kartal M, Sener B, Dvorská M, Smejkal K, Slapetová T. 2009. Cholinesterase inhibitory activities of some flavonoid derivatives and chosen xanthone and their molecular docking studies. Chem Biol Interact. 181(3):383-389.

Kim M-Y, Iwai K, Matsue H. 2005. Phenolic compositions of Viburnum dilatatum Thunb. fruits and their antiradical properties. J Food Compos Anal. 18(8):789-802.

Lane RM, Potkin SG, Enz A. 2006. Targeting acetylcholinesterase and butyrylcholinesterase in dementia. Int J Neuropsychopharmacol. 9(1):101-124.

Mehta M, Adem A, Sabbagh M. 2012. New acetylcholinesterase inhibitors for Alzheimer's disease. Int J Alzheimer Dis. 201(2):1-8.

Melchior M. 1964. Engler's syllabus der pflanzenfamilien. 12th ed. Vol. 2. Berlin (Germany): Gebr. Borntrager; p. 474.

Mohammadhosseini M, Venditti A, Akbarzadeh A. 2019. The genus Perovskia Kar.: ethnobotany, chemotaxonomy and phytochemistry: a review. Toxin Rev.

Rivière C. 2016. Dihydrochalcones: occurrence in the plant kingdom, chemistry and biological activities. Stud Nat Prod Chem. 51:253-381.

Saltan G, Süntar I, Ozbilgin S, Ilhan M, Demirel MA, Oz BE, Keleş H, Akkol EK. 2016. Viburnum opulus L.: a remedy for the treatment of endometriosis demonstrated by rat model of surgically-induced endometriosis. J Ethnopharmacol. 193:450-455.

Szwajgier D. 2014. Anticholinesterase activities of selected polyphenols - a short report. Pol J Food Nutr Sci. 64(1):59-64.

Tomassini L, Serafini M, Foddai S, Ventrone A, Nicoletti M. 2013. New acylated salicin bis-glucosides from Viburnum veitchii. Nat Prod Res. 27(13):1208-1212. 
Upton R. 2000. Black haw bark Viburnum prunifolium. Analytical, quality control, and therapeutic monograph. Santa Cruz (CA, USA): American Herbal Pharmacopoeia and Therapeutic Compendium; p. 1-17.

Van Q, Nayak BN, Reimer M, Jones PJH, Fulcher RG, Rempel CB. 2009. Antiinflammatory effect of Inonotus obliquus, Polygala senega L., and Viburnum trilobum in a cell screening assay. J Ethnopharmacol. 125(3):487-493.

Wang XY, Shi HM, Zhang L, Li XB. 2009. A new chalcone glycoside, a new tetrahydrofuranoid lignan, and antioxidative constituents from the stems and leaves of Viburnum propinquum. Planta Med. 75(11):1262-1265.

Winkworth RC, Donoghue MJ. 2004. Viburnum phylogeny: evidence from the duplicated nuclear gene GBSSI. Mol Phylogenet Evol. 33(1):109-126.

Winkworth RC, Donoghue MJ. 2005. Viburnum phylogeny based on combined molecular data: implications for taxonomy and biogeography. Am J Bot. 92(4):653-666.

Yılmaz BS, Çitoğlu GS, Altun ML, Özbek H. 2007. Antinociceptive and anti-inflammatory activities of Viburnum lantana. Pharm. Biol. 45(3):241-245. 